\title{
LOS DIFUSOS CONTORNOS DE LA INMUNIDAD DE JURISDICCIÓN EN EL ÁMBITO DEL CONTRATO INDIVIDUAL DE TRABAJO (STSJ DE MADRID DE 13 DE JULIO DE 2020)
}

\author{
THE VARIOUS CONTOURS OF THE INMUNITY \\ OF JURISDICTION IN THE FIELD OF THE INDIVIDUAL \\ EMPLOYMENT CONTRACT (THE DECISION \\ OF THE HIGHER COURT OF MADRID OF JULY 13, 2020)
}

\author{
Pilar JuÁrez PÉREZ \\ Profesora Titular de Derecho Internacional Privado \\ Universidad Carlos III de Madrid \\ ORCID ID: 0000-0003-3044-5679
}

Recibido: 15.06.2021 / Aceptado: 19.07.2021

DOI: https://doi.org/10.20318/cdt.2021.6296

\begin{abstract}
Resumen: Se analizan los motivos e implicaciones de la sentencia núm. 558/2020, dictada por el Tribunal de Justicia de Madrid el 13 de julio, donde reconoce la inmunidad de jurisdicción de la Embajada de Brasil en Madrid ante un litigio suscitado por la demanda por despido nulo presentada por un trabajador que desempeñaba funciones de auxiliar administrativo. Utilizando como principal fundamentación jurídica la LO 16/2015, sobre privilegios e inmunidades de los Estados extranjeros, el tribunal confirma la corrección de la sentencia de instancia al declarar que siendo un litigio que eventualmente puede ocasionar la readmisión del trabajador, incurre en una de las excepciones legales a la limitación inmunidad, de forma que el Estado de Brasil puede evitar el enjuiciamiento del asunto por los tribunales laborales españoles. Se plantea así la cuestión de delimitar cuáles son los contornos de la inmunidad de jurisdicción en al ámbito del contrato individual de trabajo, que a la vista de la actual regulación estatal española, parece más cerca de la inmunidad absoluta que de la restringida.

Palabras clave: contrato de trabajo internacional, trabajadores de embajadas, inmunidad de jurisdicción, Ley Orgánica 16/2015, de 27 de octubre, sobre privilegios e inmunidades de los Estados extranjeros.
\end{abstract}

\begin{abstract}
Analysis of the reasons and implications of judgment $n^{0} 558 / 2020$, issued by the Court of Justice of Madrid on July 13, where it recognizes the immunity of jurisdiction of the Embassy of Brazil in Madrid in the event of a dispute arising from the claim for null dismissal filed by a worker who performed the functions of administrative assistant. With the legal basis of LO 16/205, on privileges and immunities of foreign States, the court confirms the correctness of the judgment of instance by declaring that bien a litigation that may eventually lead to the reinstatement of the worker, it incurs one of the legal excepciones to the limitation of immunity, so the that the State of Brazil can avoid the protescution of the matter by the Spanish labor courts. This raises the question of delimiting what are the contours of immunity from jurisdiction in the área of the individual employment contract. Taking into account the current Spanish regulation, it seems closer to absolute immunity than restricted.
\end{abstract}

Keywords: international employment contract, Embassy workers, inmunity from jurisdiction, Organic Law 16/2015, of October 27, on privileges and inmunities of foreign states. 
Sumario: I. De nuevo sobre un trabajador al servicio de una embajada. II. La positivación de la inmunidad de jurisdicción en el ordenamiento español: la Ley Orgánica 16/2015, de 27 de octubre, sobre privilegios e inmunidades de los Estados extranjeros. III. La considerable amplitud de las excepciones a la inmunidad de jurisdicción en el marco del contrato individual de trabajo. IV Conclusiones: ¿un cierto retorno a la «inmunidad absoluta»?

\section{De nuevo sobre un trabajador al servicio de una embajada.1}

1. La sentencia que traemos a colación confirma la decisión de un juzgado de lo social de Madrid, que declaró la inmunidad de jurisdicción de la Embajada de Brasil en Madrid frente a un procedimiento de despido instado por un trabajador de dicha representación (autos $n^{\circ}$ 176/19 del Juzgado de lo Social $n^{\circ} 3$ de los de Madrid).

2. En febrero de 2005, el demandante había suscrito un contrato de trabajo de duración determinada eventual por circunstancias de la producción con categoría profesional de auxiliar administrativo, que se transformó en indefinido en febrero del año siguiente. Mediante carta entregada al trabajador el 21 de diciembre de 2018, la Embajada de Brasil en Madrid le comunicó la extinción del contrato de trabajo a partir de esta misma fecha, debido a la necesidad de «reducir una plaza en el sector de prensa y que sería su plaza (...)». Correlativamente, en la misma comunicación se reconocía la improcedencia del despido, con la indemnización regulada en el art. 56.1 del Estatuto de los Trabajadores (ET), y la correspondiente liquidación de haberes.

3. Frente a esta decisión, el trabajador presentó ante el órgano jurisdiccional español demanda pretendiendo la declaración de la nulidad del despido, que desestimó la posibilidad de entrar a conocer del asunto, al acoger la excepción de inmunidad de jurisdicción opuesta por la embajada demandada. En este punto, interesa apuntar que el Ministerio Fiscal se había manifestado en contra, considerando que no cabía apreciar la inmunidad de jurisdicción por tratarse de una acción judicial recaída sobre actos realizados iure gestionis, no siendo actos de soberanía realizados iure imperii. A mayor abundamiento, subrayaba el Ministerio Fiscal el hecho de que el actor ostentase la categoría de auxiliar administrativo, sin desarrollar funciones que pudiesen afectar a la soberanía estatal.

4. Sin embargo, el juzgado de lo social no compartió dicho criterio, entendiendo que siendo la readmisión del trabajador una consecuencia automática de la declaración de nulidad del despido, dicho efecto quedaba amparado por la inmunidad de jurisdicción, al constituir la excepción recogida en el artículo 10.c) de la Ley Orgánica 16/2015, de 27 de octubre, sobre privilegios e inmunidades de los Estados extranjeros, las Organizaciones Internacionales con sede u oficina en España y las Conferencias y Reuniones internacionales celebradas en España (en adelante, LO 16/2015) ${ }^{1}$. En consecuencia, no llega el órgano judicial a enjuiciar el acto extintivo del contrato de trabajo objeto del proceso, interponiendo el demandante recurso de suplicación contra dicho auto ante el Tribunal Superior de Justicia de Madrid. Como motivos del recurso, tres: infracción de los artículos 6.b) y 10.2, d) de la LO 16/2015, del artículo 63 de la LRJS y del artículo 24 de la Constitución Española, constituyendo el segundo el eje central de nuestro análisis, pues en él radica la esencia de la doctrina aquí abordada.

1 BOE núm. 258, de 28 octubre 2015. De cara a evidenciar su trascendencia, además de su carácter orgánico, nos parece oportuno subrayar que esta norma tuvo una eficacia inmediata, al no existir una disposición transitoria, desde su entrada en vigor puede ser aplicada incluso a procesos en trámite, siempre que el estado del proceso lo permita (en este sentido, STSJ Madrid núm. 556/2016, de 21 de julio (AS 2016\1433): “(...), pues el Estado extranjero tiene derecho a hacer uso de su inmunidad de jurisdicción desde que la ley está en vigor, al no haberse exceptuado a los procesos que hubieran sido iniciados con anterioridad". 


\section{La positivación de la inmunidad de jurisdicción en el ordenamiento español: la Ley Orgánica 16/2015, de 27 de octubre, sobre privilegios e inmunidades de los Estados extranjeros}

5. Como núcleo central de la presente sentencia encontramos la figura de la inmunidad de jurisdicción de los Estados, una institución nacida casi a la par que el desarrollo de las relaciones entre Estados, que se sustentaban -y evolucionaban- sobre la máxima «par in parem, non habet imperium»: los iguales no tienen jurisdicción uno sobre otro ${ }^{2}$. Sobre esta base teórico-jurídica se va desarrollando a lo largo de los siglos la figura de la inmunidad de jurisdicción y ejecución de Estados y otras organizaciones internacionales. Resulta imposible siquiera resumir aquí la evolución de esta doctrina, dada la extensión temporal del proceso y los considerables matices y casuística que la impregnan. Por eso, y a efectos de nuestro análisis baste decir que, visto en perspectiva, cabe apreciar un movimiento pendular, que va desde la inicial inmunidad absoluta a los considerables límites y restricciones que desde principios del siglo XX comienzan a acotar su ejercicio, hasta llegar a la inmunidad actual, considerablemente más restringida. En el eje de esta evolución, la distinción entre actos iure imperii/iure gestionis, que durante mucho tiempo constituyó la herramienta teórica básica para modular la inmunidad, pese a sus inherentes carencias y limitaciones ${ }^{3}$. Y ello, porque una vez que se acepta la posibilidad de demandar a los Estados surge el problema de cómo determinar si una determinada actividad escapa o no a la inmunidad de jurisdicción ${ }^{4}$.

6. Actualmente, el artículo 1 de la LO 16/2015 define la inmunidad de jurisdicción como la "prerrogativa atribuida a un Estado, organización o persona de no ser demandado ni enjuiciado por los órganos jurisdiccionales de otro Estado". Siendo su objeto principal la regulación de las inmunidades jurisdiccionales de los Estados extranjeros en España (Título I), La Ley se alinea con la tesis iusinternacionalista mayoritaria, que considera que la inmunidad de los Estados extranjeros no debe tener carácter absoluto, sino que ha de ser limitada o restringida. Tales limitaciones se sustentan sobre la distinción ya apuntada, entre actos iure imperii y actos iure gestionis, pero en lugar de acudir al sistema tradicional de delimitación judicial y caso por caso, la norma utiliza un sistema de lista, calificando de forma objetiva aquellos actos que pueden beneficiarse -o no- de la inmunidad.

7. De esta forma, el mecanismo esencial de la Ley consiste en elaborar un catálogo de excepciones a la falta de inmunidad de los Estados, permitiendo que aleguen tal privilegio en los supuestos taxativamente recogidos por la propia la norma. En consecuencia, como subraya C. GuTIÉRREz EsPADA, la LO 16/2015 opta, por una parte, por la tesis de la inmunidad de jurisdicción relativa o restringida de los Estados extranjeros ante los jueces nacionales; y por otra, a fin de precisar cuándo un Estado extranjero tiene inmunidad de jurisdicción y cuándo no la tiene, recurre a lo que el autor denomina «sistema de lista» ${ }^{6}$.

\footnotetext{
2 Como explican A.L. Calvo Caravaca/J. Carrascosa, "aunque existen precedentes anteriores, esta doctrina presenta una raíz cristiana: «toda autoridad viene de Dios» (Jn 19,11 y Rom. 13,1). Por ello, la autoridad no puede ser juzgada por ningún tribunal" (Tratado de Derecho Internacional Privado, T. 1, Tirant Lo Blanch, 2020. p. 324). Con esta raíz, la institución comienza su desarrollo jurídico, marcado por siglos de evolución y de concepciones de la propia figura, concienzudamente reflejada por los referidos autores.

${ }^{3}$ En efecto, basada en dos criterios simultáneos (la finalidad del acto y la naturaleza del acto), esta distinción ha generado no pocas dudas y críticas sobre su eficacia real. Y es que, como indica A.L. CAlvo CARAVACA, "El criterio es confuso y poco operativo, porque, en definitiva, toda actividad desarrollada por el Estado persigue una «finalidad pública»..." ("Inmunidad de jurisdicción y de ejecución”, en N. Witzleb, R. Ellger, P. Mankowski, H. Merkt y O. Remien (coords.), Festschrift für Dieter Martiny zum 70. Geburtstag, Tübinguen, Mohr Siebeck Verlag, 2014, pp. 639-661, p. 648).

${ }^{4}$ C. GutiérRez Espada, "Sobre la inmunidad de jurisdicción de los Estados extranjeros en España, a la luz de la Ley Orgánica 16/2015, de 27 de octubre", Cuadernos de Derecho Transnacional, Octubre 2016, Vol. 8, No 2, pp. 5-33, p. 9.

5 D. GonzÁlez Herrera, “¿Nadie tiene jurisdicción sobre su igual? Implicaciones de la ley española sobre privilegios e inmunidades de los Estados extranjeros, las Organizaciones Internacionales, las Conferencias y Reuniones internacionales celebradas en España”, Ars Iuris Salmanticensis, vol. 4, junio 2016, pp. 293-295, p. 294.

6 "Sobre la inmunidad de jurisdicción...", ob. cit., p. 19. Una técnica ya conocida por legisladores estatales e internacionales, conscientes de las carencias del sistema basado en la distinción de los actos estatales función de la concurrencia o no de imperium en la actividad estatal (J.A. Perea UnCETA, "La inmunidad de jurisdicción de los estados: un nuevo caso en la jurisprudencia alemana y comunitaria (asunto Ahmed Mahamdia contra República Argelina)”, Diario La Ley, № 7955, Sección Tribuna, 31 Octubre 2012, pp. 1-11, p. 3).
} 
8. La LO 16/2015 fue una norma aprobada con un significativo consenso parlamentario (205 votos a favor, 1 en contra y 11 abstenciones), que prácticamente todos los operadores jurídicos consideraron tan oportuna como necesaria, pese a no responder a una exigencia legal internacional ${ }^{7}$. Su principal bondad radica en que viene a superar el régimen eminentemente consuetudinario que venía regulando la figura de la inmunidad en España y la mayor parte de los Estados, siendo en nuestro país un sistema legal caracterizado por la pobreza normativa: así, las escasas menciones contenidas en los artículos 21 y 23 LOPJ y 36 LEC, se limitaban a realizar una remisión genérica al Derecho internacional.

9. Como explica J. Martín y Pérez de Nanclares, "el problema fundamental radicaba en que ese ordenamiento iusinternacional al que remitían las leyes internas no ofrecía una respuesta suficientemente satisfactoria". Explica el autor los diversos factores que lo ocasionaban, destacando los fracasados intentos de regular la materia con carácter universal mediante un tratado internacional, dada su insuficiencia material y su constantemente aplazada entrada en vigor, siendo tan obligado como oportuno citar aquí como ejemplo emblemático, la Convención de las Naciones Unidas sobre las Inmunidades Jurisdiccionales de los Estados y de Sus Bienes, 2 de diciembre de 20049. Como factor causante del problema cita igualmente el autor el hecho de que la normativa consuetudinaria existente resultaba difusa y de difícil concreción, y a todas luces escasa para cubrir la totalidad de la materia. Con la vocación de paliar tales carencias nace en España la LO 16/205, que en la línea con la Convención de 2004, se sustenta sobre la norma general de reconocer a la inmunidad de jurisdicción de los Estados y sus bienes ante los tribunales de otros Estados, estableciendo diversas excepciones a esta regla, entre las que incluye la renuncia.

10. Entrando ya en la estructura de la Ley, sus artículos 9 a 16 establecen «excepciones a la inmunidad de jurisdicción del Estado extranjero»: ocho artículos, ocho grupos de excepciones. Conforme a ellas, el Estado extranjero no podrá hacer valer la inmunidad ante los órganos jurisdiccionales españoles en relación con procesos relativos a transacciones mercantiles (art. 9), procesos relativos a los contratos de trabajo (art. 10), a la indemnización por lesiones a las personas y daños a los bienes (art. 11), a la determinación de derechos y obligaciones respecto de bienes (art. 12), a la determinación de derechos de propiedad intelectual e industrial (art. 13), a la participación en personas jurídicas y otras entidades de carácter colectivo (art. 14), a la explotación o cargamento de buques pertenecientes a un Estado o explotados por él (art. 15), y a los efectos de un convenio arbitral (art. 16). Ocho grupos de excepciones que reproducen, con el mismo contenido y en idéntico orden, los consagrados por la Convención de Naciones Unidas de 2005.

7 Vid. en este sentido, el Informe del Consejo General del Poder Judicial de 28 de mayo de 2015, el Informe del Consejo Fiscal de 20 de mayo de 2015, y el Dictamen 693/2015 del Consejo de Estado de 23 de julio de 2015 (textos recopilados en la obra colectiva La Ley Orgánica 16/2015 sobre privilegios e inmunidades: gestación y contenido, J. Martín y Pérez de Nanclares (dir.), Cuadernos de la Escuela Diplomática, número 55, 2016). Algunos años antes, el propio Tribunal Constitucional había apelado a la positivación del régimen de las inmunidades estatales (STC 107/1992, de 1 de julio), como recoge la propia Exposición de Motivos de la LO 16/2015: "el legislador ha recibido una abierta recomendación del propio Tribunal Constitucional para que regule el régimen de las inmunidades de los Estados extranjeros en España en aras a garantizar una mayor certeza en el ámbito jurisdiccional interno sobre la base de una doctrina restringida de la inmunidad de jurisdicción $y$ de ejecución".

8 “¿Por qué una Ley de Inmunidades? Primeras reflexiones a propósito de la pertinencia y el contenido de la Ley Orgánica 16/2015, de privilegios e inmunidades”, en La Ley Orgánica 16/2015 sobre privilegios e inmunidades..., ob. cit., p. 16.

9 B.O.C.G., serie A., Núm. 396, 18 febrero 2011. Aprobada por consenso por Resolución 59/38 de la Asamblea General, su entrada en vigor requiere la adhesión de treinta Estados, habiéndose recabado veintidós a la fecha de estas líneas. No obstante lo cual, y como señala J. FerRer LLORET: "aunque la Convención de 2004 no ha entrado en vigor, el TEDH sostiene que en virtud de las interacciones normativas propias de los procesos de formación de normas internacionales, sus disposiciones (...) son expresión del DI consuetudinario en vigor" ("La Ley Orgánica 16/2015 sobre inmunidades: ¿aporta una mayor seguridad jurídica a los operadores del Derecho? Una valoración provisional”, Revista Española de Derecho Internacional, Vol. 68/1, enero-junio 2016, pp. 73-84, p. 74). 


\section{La considerable amplitud de las excepciones a la inmunidad de jurisdicción en el marco del contrato individual de trabajo}

11. Dentro de marco general anteriormente descrito hay que centrar la cuestión nuclear que ocupa la presente decisión judicial, cuyo eje jurídico gira en torno al alcance real de la «excepción de la excepción» recogida en el artículo 10.2 LO 16/2015. Como ya se ha indicado, el actor fundamentó principalmente su recurso en la infracción de los artículos 6.b) y 10.2 de la Ley Orgánica 16/2015.

12. El primero de ellos recoge una excepción a la inmunidad de jurisdicción, estableciendo que no podrá alegarse cuando "el Estado extranjero haya intervenido en el proceso o haya realizado cualquier acto en relación con el fondo" (art. 6.b). Es lo que el precepto considera un «consentimiento tácito», que impide al Estado extranjero hacer valer la inmunidad cuando haya realizado determinados actos, entre los que se encuentra el transcrito. En su recurso, sostenía el trabajador que el hecho de que la representante de la Embajada de Brasil hubiera comparecido en el acto de conciliación previo, donde manifestó que se oponía a la reclamación por las razones que se alegarían en momento procesal oportuno. A juicio del recurrente, dicha comparecencia y manifestación constituían el supuesto de intervención en el proceso y realización de actos respecto al fondo del asunto que prevé el citado artículo 6.b).

13. Sin embargo, el Tribunal de Justicia rechaza correctamente esta alegación, pues en modo alguno cabe entender que la comparecencia en un acto previo de conciliación administrativa supone la intervención en el proceso, ni la alegación sobre futuras manifestaciones en contra de lo reclamado puede ser considerada un acto relacionado con el fondo del asunto (la nulidad del despido): "el proceso se inicia con la demanda y la comparecencia a un acto promovido precisamente por el actor mediante la denominada papeleta de demanda formulada ante el SMAC, en nada evidencia que se dé consentimiento tácito a que no entre en juego la inmunidad de jurisdicción. $Y$ al decirse en el acto de conciliación que en su momento se aducirán las razones de la oposición a la reclamación, lo que este aserto revela es que en el proceso se alegará la inmunidad de jurisdicción como motivo de oposición a la demanda".

14. Sentado lo cual, resta por examinar el eje central de la presente sentencia: el alcance de la excepción a las restricciones a la inmunidad de jurisdicción de los Estados, cuestión que subyace tras la alegada vulneración del artículo 10.2 de la Ley Orgánica 16/2015. El artículo 10 que, salvo algunas diferencias de redacción no relevantes, reproduce el art. 11 de la citada Convención de Naciones Unidas de 2 de diciembre de 2004, presenta el siguiente tener literal:

“Artículo 10. Procesos relativos a contratos de trabajo.

1. Salvo acuerdo en otro sentido entre España y un Estado extranjero, este no podrá hacer valer la inmunidad de jurisdicción ante los órganos jurisdiccionales españoles en un proceso relativo a un contrato de trabajo entre ese Estado y una persona fisica, cuando el trabajo haya sido ejecutado o haya de ejecutarse total o parcialmente en España.

2. No obstante lo dispuesto en el apartado anterior, el Estado extranjero podrá hacer valer la inmunidad de jurisdicción en los procesos a los que dicho apartado se refiere, en los siguientes supuestos:

a) Cuando el trabajador hubiera sido contratado para desempeñar funciones que supongan el ejercicio del poder público;

b) Cuando el empleado sea:

i) Un agente diplomático, según se define en la Convención de Viena sobre Relaciones Diplomáticas de 1961;

ii) Un funcionario consular, según se define en la Convención de Viena sobre Relaciones Consulares de 1963; o

iii) Un miembro del personal diplomático de una misión permanente ante una organiza- 
ción internacional o de una misión especial o que haya sido designado para representar al Estado extranjero en una conferencia internacional.

c) Cuando el proceso tenga por objeto la contratación, la renovación del contrato o la readmisión del trabajador;

d) Cuando el proceso tenga por objeto el despido del trabajador o la rescisión del contrato y una autoridad competente del Estado extranjero comunique que dicho proceso menoscaba sus intereses de seguridad;

e) Cuando el trabajador fuera nacional del Estado extranjero en el momento de interposición de la demanda, salvo que dicha persona tuviese su residencia habitual en España; o

f) Cuando el Estado extranjero y el trabajador hayan convenido otra cosa por escrito, salvo que la competencia de los órganos jurisdiccionales españoles fuese irrenunciable para el trabajador".

15. De esta forma, el apartado 2 del precepto consagra un amplísimo catálogo de excepciones, que permiten al Estado empleador acogerse a su inmunidad de jurisdicción y evitar la acción de los tribunales españoles del orden social. Un sistema que reproduce, como hemos dicho, el de la Convención de Naciones Unidas (2004), pero que no deja de sorprender desde la perspectiva del objetivo proclamado por la LO 16/2015 en su Exposición de Motivos: reducir "al mínimo imprescindible [el] efecto que dichas inmunidades tiene respecto al derecho al acceso efectivo a la justicia". Desde este punto de vista, la simple lectura del artículo 10.2 permite dibujar un ámbito de operatividad de la inmunidad en materia laboral notablemente extenso, que abarca la mayoría de los procedimientos relativos al contrato individual de trabajo, y sin duda los más relevantes.

16. Entre ellos, el que nos ocupa: “c) Cuando el proceso tenga por objeto la contratación, la renovación del contrato o la readmisión del trabajador". En el presente caso, al ser la pretensión del actor la nulidad del despido, su eventual reconocimiento hubiera llevado aparejada la readmisión del trabajador, conforme al artículo 55.6 ET. De esta forma, el litigio entra de lleno en la excepción contenida en el precepto transcrito, permitiendo al Estado de Brasil activar la inmunidad de jurisdicción para evitar ser sometido a la fiscalización del órgano judicial español. En palabras del Tribunal Superior: “(...) resulta evidente que siendo lo pretendido la readmisión del trabajador como petición principal e imperativa para la Embajada, concurre la excepción contemplada en el apartado c) del artículo 10, pues el proceso tiene por objeto la readmisión del trabajador en su anterior puesto de trabajo, siendo tal readmisión una consecuencia automática de la nulidad del despido".

17. Desde la perspectiva de la LO 16/2015, esta conclusión resulta correcta y coherente con el espíritu y la intención de la norma, que pretende otorgar a los Estados extranjeros ciertos ámbitos «blindados» a la acción de los tribunales de justicia mediante la objetivación de los supuestos cubiertos por la inmunidad. Con independencia de lo cual, no deja de ser llamativo que la excepción recogida en el apartado c) del artículo 10.2 presenta tal extensión que prácticamente abarca la mayor parte de los litigios laborales, lo que viene a consagrar una exclusión de facto del contrato individual de trabajo del ámbito de la inmunidad de jurisdicción.

18. Esta postura de la Ley española -y de la Convención de Naciones Unidas - contrasta con la tendencia mostrada por el Tribunal de Justicia de la Unión Europea (TJUE) respecto a esta cuestión. Como ya tuvimos ocasión de señalar ${ }^{10}$, la postura del TJUE sobre la posibilidad de alegar la inmunidad de jurisdicción en litigios laborales incluidos en el ámbito de aplicación material de los reglamentos comunitarios sobre competencia judicial (Reglamento $n^{\circ}$ 44/2001 y Reglamento $n^{\circ} 1215 / 2012$ ), se ha venido mostrando en consonancia con la interpretación judicial hoy mayoritaria, que ha desposeído a esta figura del carácter absoluto que tuvo en otro tiempo ${ }^{26}$. Y ello, sobre la base de la ya mencionada

${ }^{10}$ P. JuÁrez PÉrez, "De inmunidades, sumisiones y centros de trabajo: la STJUE de 19 de julio de 2012, Mahamdia c. República de Argelia", Cuadernos de Derecho Transnacional, Marzo 2013, Vol. 5, No 1, pp. 254-272. 
distinción entre actos iure imperii y actos iure gestionis, defendiendo la exclusión de los actos realizados en ejercicio del poder público del sistema normativo de la Unión Europea sobre competencia judicial internacional ${ }^{11}$.

19. Ya en el concreto ámbito del contrato individual de trabajo, esta interpretación restrictiva del alcance de la inmunidad de jurisdicción por parte de la jurisprudencia del TJUE se ha acuñado con notable frecuencia en el marco de litigios suscitados entre embajadas y sus trabajadores. De tales pronunciamientos se desprende con nitidez el compromiso del TJUE con la protección del trabajador, adoptando un posicionamiento pro operario que le lleva, incluso, a calificar a las embajadas empleadoras de «sucursal, agencia o cualquier otro establecimiento», activando con ello el foro del artículo 20.2 del Reglamento 1215/2012 para declarar la competencia de los órganos jurisdiccionales de los Estados miembros.

20. Correlativamente, el Tribunal de Justicia atiende a la naturaleza y carácter de las funciones desarrolladas por los empleados de las embajadas para establecer una sustancial distinción de cara a la posibilidad de éstas de acogerse o no a la inmunidad de jurisdicción. En esencia, esta jurisprudencia determina parte de la constatación de que siendo así que las funciones de una embajada consisten esencialmente en representar al Estado acreditante, proteger sus intereses y fomentar las relaciones con el Estado receptor, tal como establece el artículo 3 del Convenio de Viena sobre las relaciones diplomáticas, de 18 de abril de $1961^{12}$. Sobre esta premisa, establece que, al ejercer dichas funciones, y al igual que ocurre con cualquier otro sujeto de Derecho público, las embajadas pueden actuar iure gestionis y ser titulares de derechos y obligaciones de carácter civil, especialmente a raíz de la celebración de contratos de Derecho privado, lo que ocurre cuando celebran contratos individuales de trabajo con personas que no desempeñan funciones que forman parte del ejercicio del poder público ${ }^{13}$. De este modo, la clave se traslada al análisis y delimitación de las funciones que realicen las personas contratadas por las embajadas, una reflexión que dejamos aquí apuntada para retomarla más adelante, a la luz de la regulación contenida en la LO 16/2015.

21. Esta tendencia interpretativa de la inmunidad de jurisdicción en el ámbito del contrato individual de trabajo ha encontrado eco en numerosos países, entre ellos España, donde lejos de las contradicciones y vaivenes mostrados en otros aspectos ${ }^{14}$, durante largo tiempo la jurisdicción laboral vino manifestándose unánimemente a favor de la calificación de persona de Derecho privado respecto de las embajadas que actuaban como empleadoras.

11 SSTJCE de 14 octubre 1976, LTU Lufttransportunternehmen GmbH \& Co. KG, 29/76, Rec. p. 1541, apartado 4; de 16 diciembre 1980, Rüffer, 814/79, Rec. p. 1263, apartado 8; de 21 abril 1994, Sonntag, 172/91, Rec. p. 1963, apartado 20; de 1 octubre 2002, Henkel, 167/00, Rec. p. 811, apartado 26; de 14 noviembre 2002, Baten, 271/00, Rec. p. 10489, apartado 30; de 15 mayo 2003, Préservatrice foncière TIARD, 266/01, Rec. p. 4867, apartado 22; y STJUE de 15 febrero 2007, Eirini Lechouritou y otros, 292/2005, Rec. p. 1519, apartado 34. Lo que excluye, en consecuencia, los litigios donde el demandado actúa sobre una pretensión sustentada en un acto de poder público: STJCE 16 diciembre 1980, Rüffer, cit., apartados 13 y 15 : "el hecho de que el demandado actúe sobre la base de una pretensión que se basa en un acto de poder público basta para que su acción, con independencia de la naturaleza del procedi miento de que disponga al efecto con arreglo al Derecho nacional, se considere excluida del ámbito de aplicación del Convenio de Bruselas". Esta interpretación es ratificada en la STJCE de 15 febrero 2007, Eirini Lechouritou y otros, cit., apartado 41: "el hecho de que el recurso interpuesto ante el órgano jurisdiccional remitente aparezca revestido de carácter civil en la medida en que su objetivo es obtener la reparación económica de los daños materiales y morales causados a los recurrentes en el litigio principal carece de toda pertinencia".

12 BOE núm. 21, de 24 enero 1968.

13 Apartado 49 STJUE 19-07-2012, C-154/2011.

14 Vid. al respecto la insólita -y censurada- STC 140/1995, de 28 de septiembre, que rompió la doctrina mantenida hasta entonces por el Tribunal Constitucional y el Tribunal Supremo, y mayoritariamente seguida por la jurisprudencia menor, que entendían restrictivamente de la inmunidad de jurisdicción y ejecución (SSTC 107/1992, de 1 de julio; 292/1994, de 27 de octubre; SSTS de 10 febrero 1986 y 1 diciembre 1986). Una fundamentada crítica de esta decisión puede verse en A.L. CALVO Caravaca y J. Carrascosa GonzÁlez, que la califican de "paso atrás" en la jurisprudencia española en la materia y señalan que "la brecha abierta por esa escasamente acertada sentencia no ha sido seguida, afortunadamente, por la jurisprudencia posterior" (Tratado de Derecho Internacional Privado, ob. cit., p. 334). 
22. En este sentido, procede recordar las pioneras decisiones del Tribunal Supremo, sentencias de 1 de diciembre de $1986^{15}$ y 10 de febrero de $1986^{16}$, que abrazaron firmemente la tesis de la inmunidad restringida. La segunda resolvió su supuesto similar al que nos ocupa, admitiendo un recurso de casación por infracción de ley contra una sentencia que había admitido la inmunidad de jurisdicción de la Embajada de Guinea Ecuatorial en España en un litigio ocasionado por el despido de un trabajador contratado por aquella para ejercer labores de chófer. Abandonando definitivamente la tesis de la inmunidad restringida por considerarla una doctrina consuetudinaria ya caída en desuso, el TS afirmó que ésta era también la opción del legislador español, según se desprendía de la Exposición de Motivos del Real Decreto 1654/80, de 11 de julio, sobre Servicio Contencioso del Estado en el Extranjero (derogado por el Real Decreto 997/2003, de 25 de julio, que aprueba el Reglamento del Servicio Jurídico del Estado): "la doctrina de la inmunidad absoluta de jurisdicción puede considerarse ya en su etapa final (...) Hoy en día la mayor parte, sino la totalidad de los Estados, aceptan la teoría restringida de la inmunidad de jurisdicción". Tales decisiones marcaron un cambio del rumbo jurisprudencial en esta materia, derogando una interpretación anterior, que permitía acoger la inmunidad de jurisdicción de las embajadas en los litigios relativos a trabajadores a su servicio ${ }^{17}$.

23. Durante un tiempo, esta doctrina restrictiva de la inmunidad de jurisdicción sería seguida mayoritariamente por los tribunales españoles, extendiéndose incluso a la inmunidad de ejecución de los bienes de las embajadas, cuyas cuentas corrientes no quedaban amparadas de forma absoluta frente a los embargos derivados de indemnizaciones por despido de trabajadores ${ }^{18}$. En coherencia con lo cual, esta concepción limitativa se extendía a la inmunidad alegada por organizaciones internacionales, que no Estados, con las mismas restricciones y exigencias que las aplicadas a éstos ${ }^{19}$.

24. La sentencia que aquí analizamos constituye en cierto modo un nuevo giro jurisprudencial, toda vez que estima la excepción de inmunidad de jurisdicción en un procedimiento laboral iniciado como consecuencia del despido de un trabajador al servicio de una embajada extranjera en España. Sin embargo, no cabe afirmar que estemos ante un verdadero cambio de rumbo respecto de la doctrina anterior, toda vez que en el presente caso, el pronunciamiento del Tribunal se justifica en un dato esencial: el hecho de que el proceso tenga por objeto la readmisión del trabajador contratado por la Embajada de Brasil, como consecuencia de la nulidad de su despido. Y ello, como hemos visto, sobre la base jurídica que proporciona el artículo 10.2.c) LO 16/2015.

25. Desde esta perspectiva, resulta ilustrativo detenernos en la siguiente excepción prevista por la norma, contenida en su apartado d), que -como en el caso anterior- permite al Estado extranjero hacer valer su inmunidad de jurisdicción en los procesos relativos a contrato de trabajo cuando, teniendo el litigio por objeto el despido del trabajador o la rescisión del contrato, "una autoridad competente del

15 RJ $1986 \backslash 7231$.

16 RJ $1986 \backslash 727$.

17 Cfr. STS de 8 noviembre 1979 (RJ 1979\3975), que acogió la inmunidad de jurisdicción alegada por la Embajada de Kuwait en un litigio por despido de una trabajadora contratada para desempeñar funciones de secretaria.

${ }^{18}$ STSJ Madrid núm. 432/2020, de 16 junio (AS\2021\77): “(...) es lo cierto que no pueden embargarse las devoluciones correspondientes al IVA, ni tampoco las subvenciones o donaciones que el Estado Español pueda efectuar al del Nicaragua, pero, conforme a la normativa transcrita y a la doctrina constitucional si pueden embargarse las cuentas bancarias de la Embajada que no estén utilizados o destinadas a ser utilizadas en el desempeño de las funciones de la misión diplomática (...)”.

19 Vid., como ejemplo, la STS de 14 febrero 2020 (ECLI:ES:TS:2020:936), que rechaza la invocación de la inmunidad de jurisdicción realizada por la Comisión Internacional para la Conservación del Atún Atlántico, dependiente de la Organización de las Naciones Unidas para la Agricultura y la Alimentación (FAO), en el marco de una reclamación sobre extinción del contrato de trabajo. El motivo, considerar que se trataba de una controversia particular entre una empleada de nacionalidad española y una organización internacional sin que la prestación de servicio entrañase el ejercicio de los poderes públicos que a dicha entidad le corresponden, ni se tratase tampoco de un funcionario o agente diplomático, siendo en todo caso a la empleadora a la que corresponde acreditar que la trabajadora realizaba funciones de dicha naturaleza.

Sobre una organización internacional en reclamación sobre extinción del contrato de trabajo (ratifica la STSJ Madrid de 4 noviembre 2016, recurso 661/2016). 
Estado extranjero comunique que dicho proceso menoscaba sus intereses de seguridad". Con esta previsión, el precepto exige aquí un plus de justificación o fundamentación de la excepción alegada, cual es la puesta en peligro de la seguridad de la embajada ${ }^{20}$. En consecuencia, en los procesos por despido o rescisión del contrato de trabajo, la clave se traslada a la actividad probatoria del empleador, que debe acreditar la concurrencia de dicha lesividad.

26. En el caso de la excepción del artículo 10.2.d) no estamos, como en el anterior -artículo 10.2.c)-, ante un supuesto objetivo, donde basta la concurrencia de los elementos objetivos (procesos sobre contratación, renovación del contrato o readmisión del trabajador) para abrir la puerta a la prerrogativa que permite a los Estados esquivar la acción de los tribunales ordinarios. Mientras el apartado c) objetiviza la excepción, el apartado d) le exige una justificación para operar, lo que a su vez traslada la carga de la prueba a la embajada contratante.

27. Desde este punto de vista, los tribunales españoles se inclinan por una interpretación coherente con la trayectoria jurisprudencial de nuestro país en este ámbito: considerar que la alegación relativa a que "menoscaba sus intereses de seguridad" que se contiene en el artículo 10.2.d) LO 16/2015 "debe ser entendida como una excepción a la norma general que se contiene en el ordinal que le antecede, y que debe ser interpretada en sus estrictos términos". Así lo declara la STSJ Madrid de 12 febrero $2020^{21}$, dictada en un procedimiento por despido de una trabajadora contratada por la Embajada de Turquía para realizar tareas de limpiadora. La empleadora alegó la concurrencia de menoscabo para la seguridad del Estado turco sobre la base de que la libertad de movimiento de la trabadora por las dependencias de la Embajada le permitía acceder a información relevante y confidencial respecto de las actividades de la autoridad competente de Turquía. Consideraba la embajada que el desarrollo de un procedimiento judicial por despido en España podía acrecentar y agravar dicho perjuicio, invocando su inmunidad de jurisdicción para evitarlo.

28. Así fundamentada, esta alegación fue rechazada por el Tribunal, que declaró no entender "como un procedimiento laboral ante los órganos sociales de la jurisdicción española puede menoscabar los "intereses de seguridad" del Estado Turco en su condición de empleador, máxime si se tiene en cuenta que la referencia ha de venir establecida "a los asuntos relativos a la seguridad nacional y a la seguridad de las misiones diplomáticas y las oficinas consulares", como ya se ha dicho, de modo que habríamos de entender que la inmunidad pretendida por la Embajada de Turquía implicaría una extralimitación en relación a la causa que justificaría dicha inmunidad de jurisdicción ante los órganos jurisdiccionales españoles".

29. Por el contrario, la STSJ Madrid núm. 556/2016, de 21 de julio, sí apreció la concurrencia de justificación para activar la inmunidad de jurisdicción frente a un procedimiento por instado por una trabajadora empleada por la Embajada de Lituania en Madrid con cargo de administrativa, ante la no renovación de su contrato tras ocho años a su servicio. En esta ocasión, tanto la sentencia de instancia como la dictada en suplicación consideraron que procedía declarar la reclamada inmunidad de jurisdicción de la embajada "en aplicación del apartado 2.c) o en su defecto el 2.d)" del artículo 10 LO 16/2015. En puridad, al tratarse de un proceso cuyo objeto era la renovación del contrato de trabajo, el precepto aplicable era el primero de ellos, que como hemos visto no requiere de justificación ni circunstancia añadida alguna para conceder al Estado la inmunidad de jurisdicción más allá del encaje del caso en el supuesto de hecho de la norma (“Cuando el proceso tenga por objeto la contratación, la renovación del contrato o la readmisión del trabajador").

${ }^{20}$ De nuevo, la redacción de este precepto es tributaria de la contenida en la Convención sobre las inmunidades jurisdiccionales de los Estados y de sus bienes de 2004 (art. 11), cuyo anexo recoge el significado de determinadas disposiciones, estableciendo que la referencia del artículo 11.2.d) a los "intereses de seguridad" del Estado empleador es, ante todo, "una referencia a los asuntos relativos a la seguridad nacional y a la seguridad de las misiones diplomáticas y las oficinas consulares".

${ }^{21}$ ECLI:ES:TSJM:2020:776. 
30. No obstante, al ser la acción ejercitada la de despido, opta el Tribunal por valorar también la concurrencia de los requisitos exigidos por el apartado d) del artículo 10.2, estimándola en sentido positivo: de una parte, porque una autoridad competente del Estado extranjero comunica que dicho proceso menoscaba sus intereses de seguridad, "pues como se afirma en la sentencia del Juzgado, basta la comunicación sin que sea necesaria prueba alguna"; de otra, porque la embajada declarada que la demandante tenía autorización para acceder a la información clasificada como confidencial y disponía de información importante sobre las actividades generales de la Representación y sus tareas y proyectos específicos, entre otros extremos. Para el Tribunal, "ello es suficiente para considerar que concurre el supuesto del art. 2.d) sin que ello suponga una interpretación extensiva como afirma la recurrente, pues es razonable imponer al trabajador que se halla en la situación descrita que litigue contra su país ante sus propios órganos jurisdiccionales, evitando así cualquier posibilidad de difusión de tales datos en un Estado extranjero, lo que podría suceder a través de la prueba documental o de interrogatorio".

31. A la vista de esta regulación del artículo 10.2 LO 16/205, del juego de los apartados c) y d) podemos extraer la conclusión de que en cierto modo «blinda» la potestad empleadora de las personas de derecho público. En el caso de las embajadas, estas disposiciones legales constituyen además un notable freno a la doctrina judicial que venía limitando dicha potestad de forma tan imparable como implacable, sobre la base del examen casuístico del concreto contrato individual de trabajo afectado, en una permanente actualización de la distinción entre actos iure imperii y actos iure gestionis. Esta distinción -invocada por el Ministerio Fiscal en el presente caso- pierde en gran medida su carácter necesario por efecto de la regulación contenida en la LO 16/2015, cuya lista de procesos incluidos y excluidos de la inmunidad de jurisdicción simplifica notablemente el anterior proceso interpretativo, pero no necesariamente en aras de una más correcta comprensión y aplicación de la institución de la inmunidad estatal.

\section{Conclusiones: ¿un cierto retorno a la «inmunidad absoluta»?}

32. Actualmente, cabe afirmar que existe consenso en considerar que la tendencia hacia una inmunidad más restrictiva "resulta lógica a la par que necesaria" dado el considerable incremento de la actividad estatal en ámbitos antes reservados únicamente a actuaciones privadas ${ }^{22}$. A la vista de lo cual, no sería justo -ni estaría justificado- que dichos actores de las relaciones privados no pudieran ser demandados ante los tribunales, pues situaría a sus co-contratantes particulares en una "clara situación de desigualdad"23. En cierto modo, la LO 16/2015 está inspirada por dicha situación, de forma que al intentar clarificar -y limitar- las situaciones en que puedan hacer uso de su inmunidad los Estados y demás personas de derecho público, otorga una mayor previsibilidad y seguridad jurídica a las personas privadas que con ellas (con)tratan.

33. Sin embargo, la efectiva aplicación de esta norma por los tribunales del orden social permite dudar de que este objetivo esté siendo alcanzado. Limitándonos únicamente a los dos preceptos abordados (apartados c) y d) del artículo 10.2 LO 16/2015, podemos apreciar que su conjunción otorga a los Estados un amplísimo amparo en materia laboral, permitiendo que los procesos más relevantes relativos al contrato individual de trabajo puedan quedar vedados a la acción de la jurisdicción laboral. En un caso (apartado c), sin necesidad de justificación o requisito ulterior, más allá de la circunstancia objetiva de tratarse de un proceso de los enumerados por la norma. En otro (apartado d) cuando concurran dos requisitos, siendo el primero de ellos consustancial al supuesto de hecho (que sea la autoridad pública la que comunique el menoscabo de sus intereses de seguridad) y el otro, incierto y de compleja valoración, como todo concepto jurídico indeterminado (la efectiva producción de dicho daño o perjuicio), que puede derivar en las ya vistas decisiones judiciales dispares.

\footnotetext{
${ }^{22}$ C. Gutiérrez Espada, “Sobre la inmunidad de jurisdicción...”, ob. cit., p. 9.

${ }^{23}$ Ibidem.
} 
34. Lo que, a sensu contrario, restringe el ámbito de acción judicial en materia de contratos individuales a los procesos ocasionados por las modificaciones de las condiciones laborales y por el despido del trabajador ${ }^{24}$, siempre que no concurran las dos circunstancias apuntadas: manifestación de una autoridad pública y menoscabo de los intereses de seguridad. Tal fue el supuesto que resolvió la STS núm. 456/2021, de 29 de abril25, que declaró la competencia de la jurisdicción española para conocer del proceso laboral de despido, iniciado por un ciudadano español contratado en España para prestar servicios de administrativo en la Embajada de Indonesia en Madrid. En esta ocasión, el Tribunal Supremo coincidió con el pronunciamiento dictado por el Juzgado de lo Social, que había desestimado la excepción de inmunidad de jurisdicción, lo que fue anulado por el TSJ Madrid, que sí consideró procedente estimarla. Sin embargo, el Tribunal Supremo vuelve al parecer judicial inicial, aplicando la doctrina recogida en la sentencia dictada por el TJUE el 19 de julio de 2012, C-154/2011, Ahmed Mahamdia c. República Democrática y Popular ${ }^{26}$.

35. Esta doctrina determina que corresponde al órgano jurisdiccional nacional que conoce del asunto determinar la naturaleza exacta de las funciones ejercidas por el trabajador. Conforme a ello, estima el Tribunal Supremo que resulta evidente la competencia de la jurisdicción española para conocer de la acción de despido, "toda vez que una actividad administrativa de un trabajador (que en el caso, cobraba 900 euros mensuales), está totalmente alejada de funciones ius imperii”. Se vuelve aquí a la tradicional clasificación de los actos realizados por los Estados, que el TS examina si puede ser desplazada por la previsión contenida en el artículo 10.2.d) LO 16/2015.

36. Esta cuestión es enjuiciada conforme al pronunciamiento del Tribunal Europeo de Derechos Humanos de 23 de marzo de 2012, Cudak v. Lituania ${ }^{27}$, que sobre el precepto equivalente contenido en la Convención de Naciones Unidas (art. 11.2.d), interpreta que no basta con la mera alegación de que se tuvo acceso a información o documentos, para cumplir lo dispuesto en el art. 11.2.d de la Convención, "sino que es exigible la concurrencia de circunstancias objetivas que permitan inferir la concurrencia de riesgos de seguridad por la celebración del proceso". En aplicación de esta doctrina, considera el TS que, dado el carácter excepcional de la previsión del artículo 10.2.d), su aplicación requiere una justificación razonable del modo en que el proceso de impugnación de un despido de un trabajador administrativo puede poner en riesgo la seguridad de un Estado, sin que basten sus meras alegaciones en tal sentido.

37. Desde el punto de vista de la inmunidad de jurisdicción y ejecución de los Estados y otras organizaciones internacionales, resulta incuestionable la necesidad de establecer excepciones a las limitaciones de dicha prerrogativa ${ }^{28}$, otorgando a los Estados una libertad de actuación y decisión no sometida a la acción de los tribunales de justicia ${ }^{29}$. Sin embargo, en el concreto ámbito que aquí tratamos, parece cuanto menos discutible la justificación de hurtar a tal acción judicial prácticamente todas las vertientes y aspectos de la relación individual de trabajo. Acaso por un efecto perverso de la LO 16/2015, que de

${ }^{24}$ Sobre la corrección de esta consideración, desde un prisma constitucional, vid. M. GóMEZ JENE, "Inmunidad y contrato de trabajo", Revista Española de Derecho del Trabajo, num.147/2010.

${ }^{25}$ ECLI:ES:TS: 2021:1996.

${ }^{26}$ Esta sentencia resolvió una cuestión prejudicial, referida al despido de un chófer de la Embajada Argelina en Alemania, concluyendo el Tribunal la exclusión de las actividades del trabajador del ámbito de las funciones soberanas del Estado de Argelia, con la consiguiente declaración de su sometimiento a la jurisdicción alemana.

${ }_{27}$ Tribunal Europeo de Derechos Humanos, Cudak v. Lithuania, demanda núm. 15869/02 (Gran Sala, 23 de marzo de 2010).

28 Sobre esta cuestión, vid. los ilustrativos ejemplos ofrecidos por J. FERRER Lloret, "La Ley Orgánica 16/2015 sobre inmunidades: ¿aporta una mayor seguridad jurídica a los operadores del Derecho? Una valoración provisional”, Revista Española de Derecho Internacional, Vol. 68/1, enero-junio 2016, pp. 73-84.

29 STS núm. 339/2018, de 22 de marzo (RJ 2018\1634), que reitera la doctrina del Tribunal Constitucional en la que se afirma que la inmunidad de los Estados extranjeros no es contraria al derecho a la tutela judicial efectiva consagrado por el art. 24.1 CE, "en la medida en que ésta se ajuste a lo dispuesto en el art. 21.2 LOPJ, esto es, siempre que la inmunidad pretendida no implique una extralimitación en relación a la causa que justificaba dicha inmunidad (SSTC 107/1992, RTC 1992\107; 292/1994, RTC 1994\292; y 18/1997, RTC 1997\18)”. 
partida pretende lo contrario, el juego de sus normas en materia laboral permite en la práctica consagrar una suerte de «inmunidad absoluta», especialmente en los procesos relativos a contratación, renovación del contrato o readmisión del trabajador: en ellos la inmunidad puede ser activada por la mera concurrencia de la acción del trabajador, sin necesidad de que concurra una justificación reforzada -o específica- para dicha inmunidad. De ahí la trascendencia de la interpretación realizada por el Tribunal Supremo en su sentencia de 29 de abril de 2021, que a nuestro juicio encamina la aplicación de esta normativa por la senda correcta conforme a la verdadera esencia y justificación de la inmunidad de jurisdicción.

38. En el ámbito laboral, el argumento que a priori sustenta esta excepción a la inmunidad de jurisdicción estatal restringida -hurtando así del conocimiento de los tribunales nacionales el contrato de trabajo- lo encontramos en el artículo 7 de la Convención de Viena sobre las relaciones diplomáticas (1961), que concede al Estado acreditante tiene la potestad de nombrar libremente al personal de su Misión $^{30}$. La razón fundamental es que cualquier miembro de la Misión puede ser declarado persona non grata o no ser aceptado antes de su entrada en el Estado receptor. Esta potestad se refleja con especial intensidad en el artículo 10.2.c) LO 16/2015, que viene "a confirmar el principio de inmunidad en el ejercicio del poder discrecional de nombramiento o no nombramiento de una persona a cualquier puesto oficial o empleo" ${ }^{\prime \prime}$.

39. Sin embargo, llevada al extremo, esta consideración implica desposeer al contrato laboral de su naturaleza de contrato de derecho privado, susceptible de conocimiento por los tribunales nacionales. La consecuencia inmediata es facultar a los Estados para nombrar a su personal en el extranjero y fijar sus condiciones laborales sin supervisión judicial alguna, y esta ausencia de control resulta especialmente llamativa cuando estamos ante procesos laborales instados por trabajadores que no desarrollan labores directa o colateralmente relacionadas con las funciones diplomáticas, sino que ejecutan lo que constituyen labores de gestión por antonomasia: secretaría, limpieza, transporte, mantenimiento etc. Cuesta detectar en el desarrollo de tales funciones una afectación de los «intereses de seguridad» de las embajadas que pueda justificar la proscripción de someter la relación laboral de estos trabajadores al enjuiciamiento y control de los tribunales de justicia. Y ello, en el más estricto de los supuestos (apartado d), que exige dicha justificación, pues en los procesos no relativos al despido o la rescisión del contrato no resulta exigible a siquiera dicha justificación a los Estados, que quedan amparados por la inmunidad de jurisdicción con su mera invocación ante los tribunales de justicia.

40. De lege ferenda, acaso hubiera sido preferible que ambos supuestos, los recogidos en los apartados c) y d), se hubieran unificado bajo unas mínimas exigencias -siquiera las ya vigentes- para justificar esta «desaparición» en la práctica de la inmunidad de jurisdicción en el ámbito del contrato individual de trabajo. Además de que conceptualmente resulta difícil defender la distinción de procesos hoy recogida por la Ley, esta regulación otorgaría a los tribunales de justicia un margen valorativo para enjuiciar la procedencia de la inmunidad del empleador frente al trabajador, que en un ámbito como el del contrato individual de trabajo resulta tan imprescindible como irrenunciable ${ }^{32}$.

${ }^{30}$ A. Oliva IzQuierdo, "La inmunidad de jurisdicción y ejecución en el Derecho laboral español: su relación con el artículo 7 de la Convención de Viena de 1961”, en La Ley Orgánica 16/2015 sobre privilegios e inmunidades, ob. cit., pp. 195-203, p. 199.

${ }_{31} \mathrm{Ibidem}$, si bien la autora hace esta reflexión en relación con el precepto equivalente de la Convención de 2004: su artículo 11.2.c): "si el objeto del proceso es la contratación, la renovación del contrato de trabajo o la reposición de una persona natural".

${ }^{32}$ En este sentido, procede citar el análisis tan crítico como certero que de la LO 16/2015 realiza J.A. GonZÁLEZ VEGA, a la que, entre otras muchas cuestiones, objeta lo siguiente: "Con carácter general debe afirmarse que el texto se inspira ante todo en la idea de no perturbar las relaciones internacionales de nuestro Estado con el riesgo evidente de favorecer conceptos espurios como el «poder exterior» -no controlable democráticamente - o la «razón de Estado». Desde esta perspectiva, la regulación podría deparar en el futuro conflictos con la idea del Estado social y democrático de Derecho que nuestra Constitución pro- clama y desde luego se muestra poco atenta a las cuestiones vinculadas con la protección de los derechos fundamentales - el de tutela judicial efectiva a la cabeza-y a los desarrollos, bien que incipientes, que prefiguran recientes tendencias del DI, tal como la jurisprudencia de algún Estado próximo ha puesto de manifiesto" ("Inmunidades, Derecho internacional y tutela judicial en la Ley Orgánica 16/2015, de 27 de octubre, sobre inmunidades. ¿Juego de espejos en el callejón del gato?, Revista Española de Derecho Internacional, Vol. 68/1, enero-junio 2016, pp. 85-97, p. 87). 
41. Desde un punto de vista metodológico, acaso el sistema de lista que consagra la LO 16/2015 aporte una mayor previsibilidad y seguridad jurídicas frente a la tradicional -casuística e incierta- distinción acta iure imperii/iure gestionis. Sin embargo, desde la óptica del ya citado objetivo legal de reducir al "mínimo imprescindible" el ámbito y el alcance de la inmunidad respecto del "derecho de acceso efecto a la justicia" (Exposición de Motivos), la amplitud y falta de concreción del catálogo de excepciones a esa regla consagradas por dicha ley en el ámbito del contrato individual de trabajo permite cuestionar su eficacia real para lograr tal objetivo. 